\title{
TUBERCULOSE MONORRESISTENTE: UM ESTUDO DE CASO
}

Débhora Ísis Barbosa e SILVA ${ }^{1}$

Felipe Artur Gomes de ASSIS ${ }^{2}$

Ana Cristina Nóbrega Silva FALCÃO ${ }^{3}$

${ }^{1}$ Enfermeiro. Especialistas em Saúde da Família. Residentes do Programa de Enfermagem em Pneumologia - SES / PE

- Hospital Otávio de Freitas.

${ }^{2}$ Enfermeiro. Especialistas em Saúde da Família. Residentes do Programa de Enfermagem em Pneumologia - SES / PE

- Hospital Otávio de Freitas.

${ }^{3}$ Enfermeira Pneumologista. Coordenadora do Programa de Tuberculose do Município de Palmares e do Ambulatório

de Tuberculose Multirresistente do Hospital Otávio de Freitas - SES/PE.

Recebido em: 03/08/2015 - Aprovado em: 03/01/2016 - Disponibilizado em: 30/07/2016

RESUMO: Relata-se um caso de Tuberculose monorresistente, em uma mulher de 50 anos portadora da síndrome da imunodeficiência adquirida (SIDA), cujo tratamento iniciou com o esquema básico em uma unidade de saúde da família. Tal estudo teve como objetivo a realização de uma análise comparativa entre as informações disponíveis na literatura acerca do Tratamento para Tuberculose Monorresistente e o tratamento ofertado ao paciente. Realizou-se resgate de prontuário do paciente acompanhado no Ambulatório de Tuberculose Multirresistente. A correta condução do caso juntamente com o uso correto das drogas escolhidas para o tratamento, aprimora a estratégia de cura para a tuberculose em tempo hábil.

PALAVRAS - CHAVE: Tuberculose; Tuberculose Pulmonar; Tuberculose Resistente a Múltiplos Medicamentos ; Síndrome de Imunodeficiência Adquirida; Estudo de Caso

\section{TUBERCULOSIS MONORRESISTENTE: A CASE STUDY}

ABSTRACT: We report a case of multidrug-resistant tuberculosis in a woman of 50 years carrying the acquired immunodeficiency syndrome (AIDS), whose treatment started with the basic outline in a family health unit. This study aimed to carry out a comparative analysis of the available information in the literature about the treatment for TB Monorresistente and treatment offered to the patient. Held patient record rescue joined on Multidrug Tuberculosis Clinic. The proper conduct of the case along with the proper use of the drugs chosen for treatment, improves healing strategy for tuberculosis in a timely manner.

KEYWORDS: Tuberculosis; Pulmonary tuberculosis; Tuberculosis, Multidrug-Resistant; Acquired Immunodeficiency Syndrome; Case study

\section{CONSIDERAÇÕES INICIAIS}

A tuberculose (TB) é uma doença

infecto-contagiosa que se propaga através do ar por meio de gotículas contendo mycobacterium tuberculosis (Bacilo de Koch) expelidas por um doente bacilífero, nunca tratado ou em fase inicial de tratamento, ao tossir, espirrar ou falar, o que pode provocar a infecção tuberculosa, e desta forma o risco de desenvolver a doença. ${ }^{(1)}$

Uma doença milenar, apresenta-se de forma grave, mas curável em praticamente 
todos os casos novos, desde que obedecidos os princípios da quimioterapia. A associação medicamentosa adequada, a dosagem correta, seu uso por tempo suficiente e a adesão ao tratamento são os meios para evitar a persistência bacteriana e o desenvolvimento de resistência às drogas. ${ }^{(2-4)}$

O Brasil faz parte de um dos 22 países priorizados pela OMS que concentram $80 \%$ do total de casos de tuberculose no mundo. Estima-se que um em cada quatro brasileiros esteja infectado pelo bacilo de Koch e, todo ano, cerca de 90.000 novos casos da doença são notificados ao Ministério da Saúde. ${ }^{(5,6)}$

Apesar dos esforços e de alguns avanços no controle da tuberculose, a TB farmacorresistente constitui atualmente um importante problema de Saúde Pública. Nos últimos 20 anos, os estudos da Organização Mundial de Saúde (OMS) têm sinalizado um significativo incremento da TB resistente, representando um sério obstáculo para o controle da doença, especialmente em áreas onde suas prevalências são altas. ${ }^{(7)}$

O agravamento da TB farmacorresistente é frequentemente atribuída à falência de implantação de adequados programas de controle da TB e correto manejo de casos da doença. Portanto, as resistências em TB são um fiel reflexo da má qualidade dos programas de controle e consequência direta das más práticas terapêuticas de utilização de medicamentos anti-TB e para a descoberta das resistências aos fármacos antituberculostáticos, torna-se necessário a realização do exame de baciloscopia do escarro com teste de sensibilidade. $^{(5)}$

A indicação deste teste tem como finalidade a descoberta da resistência a algum ou alguns fármacos utilizados no tratamento da tuberculose e é recomendado para pacientes com baciloscopia positiva que não se torna negativa após três meses de tratamento, para pacientes com baciloscopia negativas e que voltam a ser positiva durante o tratamento para TB e para aqueles tratados previamente para TB, isto é, nos casos de recidiva. Serão ainda candidatos a este teste os pacientes HIV positivo / AIDS e tuberculose, e aqueles que por ventura manterem contato com pacientes com suspeita de TB resistente ou TB resistente confirmada. $^{(8)}$

O processo de resistência se dá por quatro mecanismos: conjugação, transformação, transdução e mutação. A conjugação é a transferência de material genético entre duas bactérias, a transdução é a transferência de material genético entre duas bactérias feita por um vírus bacteriófago, a transformação é a incorporação de um material genético livre no meio por uma célula bacteriana e mutação é uma alteração 
súbita e herdável na estrutura do material genético. $^{(9)}$

Resistência às drogas é uma ameaça aos programas de tuberculose em todo o mundo. Pacientes infectados com cepas resistentes às drogas antituberculostáticas têm menor probabilidade de se curarem, particularmente se estão infectados pelo HIV ou sofrem de outra imunopatia. ${ }^{(10)}$

Considera-se monorresistência aquele indivíduo que é portador de cepas resistente à isoniazida ou rifampicina. A ocorrência de um organismo mutante à isoniazida $(\mathrm{H})$ acontece para cada $10^{5}$ ou $10^{6}$ bacilos e a de um mutante à rifampicina $(\mathrm{R})$, para cada $10^{7}$ ou $10^{8}$ bacilos. A resistência à $\mathrm{H}$ se deve à mutação mais frequentemente observada no gene katG, e vários estudos indicam que as mutações no katG são responsáveis por cerca de $60 \%$ dos casos de cepas resistentes à $\mathrm{H}$ isoladas de pacientes. $\mathrm{A}$ resistência à $\mathrm{R}$ é pouco comum e dificilmente ocorre de forma isolada. ${ }^{(8,11,12,14)}$

Com a finalidade de monitorar a ocorrência de casos de resistência aos medicamentos anti-TB, o Programa Nacional de Controle da Tuberculose (PNCT) atualmente recomenda que os pacientes portadores de qualquer padrão de resistência sejam acompanhados na unidade de referência e notificados no Sistema de Informação de Tratamentos Especiais da TB (SITE-TB). De acordo com o último boletim epidemiológico, publicado no ano de 2014, foram notificados e acompanhados no sistema 260 casos novos de monorresistência ${ }^{(7)}$. $\mathrm{O}$ esquema recomendado pelo PNCT para os casos de monorresistência são assim descritos:

- Resistência à R: 2HZES /10HE*

- Resistência à H: 2RZES / 4RE

\section{OBJETIVO}

Este estudo de caso tem como objetivo a realização de uma análise comparativa entre as informações disponíveis na literatura acerca do Tratamento para Tuberculose Monorresistente e o tratamento ofertado ao paciente deste estudo, da atenção básica à atenção terciária.

\section{PERCURSO METODOLÓGICO}

Realizou-se resgate de prontuário do paciente acompanhado no Ambulatório de Tuberculose Multirresistente de um Hospital Escola de Referência em Pneumologia/Tisiologia de Pernambuco entre 2011 e 2012. Os dados foram obtidos por meio de prontuário, histórico da avaliação do serviço social, exames laboratoriais e de imagem, contextualizando e agrupando 
informações sendo este um estudo exploratório-descritivo e retrospectivo.

\section{ESTUDO DE CASO}

Doméstica de 50 anos, viúva, mãe de três filhos, tem um irmão e reside na Região Metropolitana do Recife, portadora de HIV/AIDS, com a confirmação em setembro de 2010, realizou acompanhamento em um hospital escola de referência para doenças infecto-contagiosa no estado de Pernambuco.

Teve seu primeiro diagnóstico de tuberculose pulmonar confirmado, através da baciloscopia positiva $(++)$ no material do escarro em junho de 2010, em uma Unidade Básica de Saúde da Família da Zona Norte do Recife. No primeiro tratamento realizado nesta Unidade Básica de Saúde foi prescrito o esquema de rifampicina, isoniazida $\mathrm{e}$ pirazinamida por três meses sem sucesso baciloscopia $(++)$.

Em setembro de 2010, foi reiniciado o esquema básico (rifampicina, etambutol, isoniazida e pirazinamida) por quatro meses, no terceiro mês de tratamento, foi realizada uma baciloscopia de controle e no quarto mês a primeira cultura de escarro e ambas com resultado negativo para BAAR.

Em janeiro de 2010, ela terceira vez, foi reiniciado o tratamento com o esquema básico para tuberculose (dose fixa combinada), desta vez no Hospital Otávio de Freitas após internamento e resultado de baciloscopia de escarro (+) em 03.01.2011 e cultura de escarro (+) em 05.01.2011 com atraso no resultado do teste de sensibilidade que evidenciou resistência à isoniazida $(\mathrm{H})$ em abril de 2011.

Em 01 de abril de 2011, volta a ser internada no hospital de referência para doenças infecto-contagiosa e deu inicio a um esquema alternativo da seguinte forma conforme descrição - Rifampicina (R), Etambutol (E), Ofloxacino (Oflx), Estreptomicina $(\mathrm{S})$ :

- $1^{\circ}$ mês (abril/2011): $\mathrm{R}+\mathrm{E}+\mathrm{S}$

- $2^{\circ}$ mês (maio/2011): R + E+ Oflx

- $\quad 3^{\circ}$ mês (junho/2011):R + E + Oflx

- $\quad 4^{0}$ mês (julho/2011):sem medicação

- $5^{\circ}$ mês (agosto/2011): R + E + S

Em setembro de 2011, foi encaminhada para o ambulatório de um outro Hospital Escola, de referência em tratamento de tuberculose resistente, apresentando dor torácica, tosse, pouca secreção amarelada e referindo episódios de febre há três dias. Iniciou esquema para monorresistência em 28.09.2011 com as seguintes medicações: 2RZES / 4RE, tendo recebido alta por cura em $\operatorname{março/2012.~}$ 


\section{DISCUSSÃO}

A paciente em estudo, concluiu o tratamento para TB Monorsesistente em 6 meses, após iniciar as medicações no Ambulatório de Referência em Tuberculose Multirresistente, Recife- PE, comparecendo a algumas consultas mensais (do $1^{\circ}$ mês ao $4^{\circ}$ mes), sendo faltosa nas consultas do $5^{\circ}$ e $6^{\circ}$ mês onde a medicação foi resgatada pelo filho, pois a paciente durante o tratamento teria que vir acompanhada já que estava apresentando um quadro de tontura $\mathrm{e}$ impossibilitando a saída de sua residência sem auxílio.

Durante todo o tratamento a paciente se queixou de dor torácica, tosse leve e ocasional, apresentou anorexia importante, astenia e alopecia. Para a dor torácica estava sendo medicada com tylex e dipirona.

A assistência e o acompanhamento do Tratamento Diretamente Observado (TDO) estava sendo realizada pela Unidade de Saúde da sua área de corbertura recebendo ajuda financeira para sua locomoção até o Ambulatório de TB Multirresistente, contudo, não havia ajuda de custo para o seu acompanhante.

Comparece ao ambulatório de referência para tuberculose resistente 2 meses após concluir o tratamento, oficializando a sua alta por cura. No momento desta consulta a paciente ESTUDOu que sentiu sua mama esquerda endurecida (quadrante superior esquerdo), que apresentava bastante dolorosa à palpação e ainda não havia começado os antirretrovirais (pendências de coleta de carga viral e CD4). Foram solicitados radiografia de tórax, Ultrassonografia de mamas, mamografia e Baciloscopia de escarro (conduta médica), mas a paciente não mais retornou impossibilitando a continuidade do tratamento.

\section{CONSIDERAÇÕES FINAIS}

Atualmente, considera-se a tuberculose um grande desafio para a saúde pública e vem exigindo o desenvolvimento de estratégias para o seu controle. Contribui para este fato as desigualdades sociais, insuficiência de pesquisas visando o desenvolvimento de novos tratamentos e vacinas, fluxos migratórios, deficiências do sistema de saúde e alta prevalência dos casos de tuberculose multidrogarresistentes e associados à infecção pelo HIV. ${ }^{(11)}$

Há muito se sabe que o indicador clínico de desenvolvimento de resistência é o contato prévio com os fármacos. Assim, a resistência é um fenômeno biológico iatrogênico, decorrente da aplicação inadequada dos regimes de tratamento de curta duração - especialmente os compostos 
pela associação de rifampicina, isoniazida, pirazinamida e etambutol. A estratégia de prevenção das resistências é a correta aplicação dos tratamentos chamados de $1^{\mathrm{a}}$ linha e de curta duração, sendo fundamentados pela estratégia do Tratamento Diretamente Observado (TDO). ${ }^{(13)}$

É fundamental que os profissionais de saúde saibam como conduzir um caso de resistência, seja ela, monorresitência (resistência a $\mathrm{R}$ ou $\mathrm{H}$ ), polirresistência (resistência a $\mathrm{R}$ ou $\mathrm{H}$ e a um outro fármaco de $1^{\mathrm{a}}$. Linha) ou multirresistência (resistência a $\mathrm{R}$ e $\mathrm{H}$ ) para que se consiga a interrupção da multiplicação do mycobacterium tuberculosis, já que dos quatro mecanismos dos quais se dá a resistência (conjugação, transformação, transdução e mutação), o bacilo da tuberculose adquire resistência aos fármacos por mutação.

O grande desafio para estas mutações são justamente a dificuldade de cura. $\mathrm{O}$ conhecimento da condução frente a um caso de resistência e o uso correto das drogas escolhidas para o tratamento, aprimora a estratégia de cura para tal em tempo hábil.

\section{REFERÊNCIAS}

\section{Sociedade Brasileira de} Pneumologia e Tisiologia; Manual de
Pneumologia: Consultas Rápidas.

Porto Alegre: ed. dos autores; 2002.

\section{Sociedade Brasileira de}

Pneumologia e Tisiologia: Centro de Referência Professor Hélio Fraga. Controle da tuberculose: uma proposta de integração ensino-serviço. Rio de janeiro, 2002.

3. Jornal Brasileiro de Pneumologia; Perfil de Resistência de mycobacterium tuberculosis no Estado de Mato Grosso do Sul 2002-2006, 2010;36(2):157-158.

4. Jornal Brasileiro de Pneumologia; Perfil de sensibilidade e fatores de risco associados à resistência do Mycobacterium tuberculosis, em centro de referência de doenças infecto-contagiosas de Minas Gerais, 2006; 32(5): 430-7.

5. Brasil. Ministério da saúde. Secretaria de Vigilância em Saúde. Manual de recomendações para o controle da tuberculose no brasil; Brasília, 2011.

6. Jornal Brasileiro de Pneumologia; Emergência de Tuberculose Resistente: renovado desafio, 2010; 36(2): 157-158.

7. Boletim Epidemiológico - Secretaria de Vigilância em Saúde - Ministério da Saúde - Detectar, tratar e curar: desafios e estratégias brasileiras frente à tuberculose - Volume 46 $\mathrm{N}^{\circ} 9-2015$.

8. ROSSETI, MLR et al.; Tuberculose Resistente: revisão molecular, Revista Saúde Pública 2002; 36(4): 525-32.

9. BAPTISTA, MGFM; Tese de Mestrado em Ciências Farmacêuticas - Mecanismos de Resistência aos Antibióticos - Lisboa 2013. Disponível em: http://recil.grupolusofona.pt/bitstream/ 
handle/10437/3264/Mecanismos\%20d e\%20Resist\%C3\%AAncia\%20aos\%2 0Antibi\%C3\%B3ticos\%20\%20Maria \%20Galv\%C3\%A3o\%20Ba.pdf?seque $\underline{\text { nce }=1}$

10. Jornal Brasileiro de Pneumologia; Papel da tuberculose domiciliar no surgimento da tuberculose multirresistente; 30(1): jan-fev de 2004.

11. PASCHUALINOTO, Ana Luiza; SILVA, Regina Ruivo Ferro, CARMO, Andréia Moreira Santos. Padrões de resistência a fármacos em pacientes com tuberculose pulmonar. Revista Brasileira de Ciências da Saúde, ano 10, nº 31, jan/mar 2012.

12. CONDE, Marcus; FITERMAN, Jussara; LIMA, Marina. Sociedade

\section{Brasileira de Pneumologia e}

Tisiologia. ed. Guanabara, Koogan, Rio de Janeiro 2011.

13. DALCOLMO M.P et al. Tuberculose multirresistente no Brasil: histórico e medidas de controle, Revista Saúde

Pública; 2007; 41(Supl. 1):34-42.

14. NATAL S. et al.; Resistência à isoniazida e rifampicina e história de tratamento anterior para a tuberculose, Caderno de Saude Pública, 19(5): 1277-1281, Rio de Janeiro, 2003

15. PASCHUALINOTO, Ana Luiza;

SILVA, Regina Ruivo Ferro, CARMO, Andréia Moreira Santos.

Padrões de Resistência a Fármacos em
Pacientes com Tuberculose Pulmonar.

Rev Bras Ciências Saúde. 2012;

10(31): 67-70. 